\title{
Neonatal screening for cystic fibrosis in Wales and the West Midlands: 1. Evaluation of immunoreactive trypsin test
}

\author{
H C RYLEY,* S M DEAM,$*$ J WILLIAMS, $\dagger$ M ALFAHAM,$\ddagger$ PH WELLER,$\dagger$ \\ M C GOODCHILD, $\ddagger$ R A CARTER,§ D BRADLEY, J J DODGE
}

From the Departments of *Medical Microbiology, $\ddagger$ Child Health, and $\|$ Medicine, University of Wales College of Medicine, Cardiff; the $\ddagger$ Children's Hospital and Institute of Child Health Birmingham; the §Pathology Laboratory, Hollymoor Hospital, Birmingham; and the INuffield Department of Child Health, Institute of Clinical Science, The Queen's University of Belfast, Belfast, Northern Ireland

SUMmaRY A study programme was set up in Wales and the West Midlands to evaluate serum immunoreactive trypsin screening for cystic fibrosis in neonates using blood spots collected for metabolic screening. By screening half the blood spots from each area, it was hoped to generate two comparable groups of fibrocystic children; those detected by screening and those not screened who would be diagnosed clinically. Over almost three years, more than 120000 specimens were screened and 37 infants detected with cystic fibrosis. Four additional fibrocystic patients were missed on screening: two had negative immunoreactive trypsin values, of which one had meconium ileus, and two, although giving initial positive tests, were negative on follow up. Excluding infants known to be at risk, comparison of the numbers of children detected in the screened and unscreened groups showed more than a two-fold difference in favour of the screened group. There may be a large number of undiagnosed fibrocystic patients in the general population.

Following the observation by Crossley et al that serum immunoreactive trypsin (IRT) was two to five times higher in the blood of neonates with cystic fibrosis compared with that in blood from healthy newborn infants, prospective studies of neonatal screening based on detection of IRT, show that the test is reliable, with less than $10 \%$ of false negative results. ${ }^{23}$ The test can be carried out on dried blood spots similar to those already collected for phenylketonuria (PKU) and hypothyrodism screening, and thus national screening for cystic fibrosis could be integrated into the existing national genetic screening programme. Although cystic fibrosis meets most of the criteria of a genetic disease which should be screened for in the neonate, ${ }^{4}$ it has still not been confirmed that the course of cystic fibrosis is improved by early treatment. Studies relating to the prognosis of infants with cystic fibrosis who have been diagnosed early, either by neonatal screening or as siblings of known patients, have usually concluded that there are some clinical benefits. ${ }^{56}$ Comparable groups were not

Accepted for publication 18 February 1988 studied, however, and the groups studied may not have been representative of selected populations of fibrocystic patients.

Since January 1985 we have been screening neonatal blood spots collected from Wales and the West Midlands to evaluate the IRT test and to determine the clinical value, if any, of early detection of the disease. To achieve this second objective, we randomly analysed half the blood spots from either region, thus generating two comparable groups of screened and unscreened patients with cystic fibrosis.

In this report we describe our experience of neonatal screening for cystic fibrosis over two years and nine months using the Behring radioimmunoassay kit for blood spot IRT assay.

\section{Material and methods}

The regions covered by this screening study are Wales and the West Midlands. Blood spots from heel pricks were collected on to filter paper by community midwives, seven to 10 days after birth and then sent to the appropriate regional screening centre. IRT 
analysis was carried out on one of the spare spots after screening for indications of PKU and hypothyroidism had been carried out, and performed on alternate weeks for each region, resulting in a random screen of half the infants born in Wales and the West Midlands.

The central Birmingham area has a separate neonatal screening laboratory and specimens collected from this area were not included in the study. Initially we did not think that this exclusion would affect our findings. The Birmingham Children's Hospital is sited in central Birmingham and infants with meconium ileus are referred from the surrounding region. These infants were in hospital when blood was taken for routine screening and were therefore not screened by the West Midlands neonatal screening centre but by the Birmingham central screening laboratory. They were thus excluded from possible random selection in this study. This has resulted in an abnormally high incidence of neonates with cystic fibrosis and meconium ileus in the unscreened group with a possible underestimation of the incidence of cystic fibrosis in the West Midlands area, calculated from infants detected by screening.

\section{ASSAY OF IMMUNOREACTIVE TRYPSIN}

The IRT assay on dried blood spots was carried out using the Behring neonatal trypsin radioimmunoassay kit (Behringwerke, Marburg, West Germany). The procedure used was a modification of that suggested by the manufacturer. The antibody and radio tracer (trypsin- $\mathrm{I}^{125}$ ) were made up into solution according to the 'manufacturer's protocol except that $0.2 \%$ Tween 20 was substituted for $1 \%$ albumin in the phosphate buffered saline (PBS) solution. The Pansorbin was extensively washed and made up to a final concentration of $0.25 \%$ in PBS.

The assay was carried out on $4.25 \mathrm{~mm}$ blood spot discs with duplicate spots for standards and quality control specimens and single spots for test specimens. After incubation on $\mathbf{0 . 2} \mathrm{ml}$ of antibody for six hours $0.1 \mathrm{ml}$ of tracer solution was added and incubation continued overnight. The following day $2 \mathrm{ml}$ of Pansorbin suspension was added to each tube and after mixing and standing for 15 minutes the tubes were spun in an MSE Mistral 3000 centrifuge at $300 \times$ $g$ for 15 minutes. After decanting the supernatant the tubes were counted for 90 seconds each in a LKB CompuGamma gamma counter fitted with an RIA mode using the spline fit option to fit the standard curve and calculate the IRT content in the test specimens. Two quality control specimens were included within the assay, one with a value of about $300 \mathrm{ng} / \mathrm{ml}$ and one with a value of about $800 \mathrm{ng} / \mathrm{ml}$. The intrabatch and interbatch coefficients of variation for the two controls were $10 \%$ and $9 \%$ and $14.5 \%$ and $15 \%$, respectively.
THE SCREENING PROTOCOL

Blood spots collected from newborn infants were assayed in Cardiff about three weeks after collection. If the first specimen was positive (IRT value of $>900$ $\mathrm{ng} / \mathrm{ml}$ ) a second specimen was requested and collected by the visiting community midwives. The age of the infant when the second specimen was collected varied between five and eight weeks. If the second specimen was considered to be positive (IRT value of $>600$ $\mathrm{ng} / \mathrm{ml}$ ) a sweat test was performed, with confirmation of the diagnosis of cystic fibrosis being achieved by the age of 12 weeks.

Diagnosis of cystic fibrosis in the unscreened infants was made on the basis of clinical manifestations of the disease and confirmed by sweat tests.

Ninety five per cent confidence limits of incidence of disease were estimated, based on the assumption that the distribution of the occurrence of cystic fibrosis is compatible with a Poisson distribution. ${ }^{7}$ Tests of significance were carried out using a $\chi^{2}$ test.

\section{Results}

\section{DETECTION OF FIBROCYSTIC INFANTS BY}

SCREENING

The results from the analysis of 120000 blood spot specimens are summarised in table 1 . Thirty seven children with confirmed cystic fibrosis were detected and four other infants with cystic fibrosis were negative by the screening protocol used. Two of these infants had first blood spot IRTs within the normal range but one of the infants also had meconium ileus (table 2). The other two of the four "false negative"

Table 1 Distribution of specimens screened between January 1985 and November 1987

\begin{tabular}{|c|c|c|c|}
\hline & $\begin{array}{l}\text { West } \\
\text { Midlands }\end{array}$ & Wales & Total \\
\hline \multirow{4}{*}{$\begin{array}{l}\text { Total No of specimens } \\
\text { Specimens with IRT of } \\
>900 \mathrm{ng} / \mathrm{ml} \\
\text { on first test } \\
\text { Specimens regarded as positive } \\
\text { in repeated tests } \\
\text { Specimens positive on second } \\
\text { test with confirmed cystic } \\
\text { fibrosis }\end{array}$} & 75817 & 52761 & 128578 \\
\hline & $\begin{array}{c}341 \\
(0.45 \%)\end{array}$ & $\begin{array}{c}133 \\
(0.25 \%)\end{array}$ & $\begin{array}{c}474 \\
(0 \cdot 37 \%)\end{array}$ \\
\hline & 27 & 17 & 44 \\
\hline & 23 & 14 & 37 \\
\hline \multirow{2}{*}{$\begin{array}{l}\text { Specimens false positive on } \\
\text { first test } \\
\text { Specimens false positive on } \\
\text { second test }\end{array}$} & $\begin{array}{c}316 \\
(0.42 \%)\end{array}$ & $\begin{array}{c}119 \\
(0.23 \%)\end{array}$ & $\begin{array}{c}435 \\
(0 \cdot 34 \%)\end{array}$ \\
\hline & 4 & 3 & 7 \\
\hline False negative results & $2^{*}$ & 2 & 4 \\
\hline $\begin{array}{l}\text { Incidence of cystic fibrosis } \\
\text { in screened population } \\
\text { Confidence limits }\end{array}$ & $\begin{array}{l}1: 3033 \\
2053-4688\end{array}$ & $\begin{array}{l}1: 3298 \\
2031-5770\end{array}$ & $\begin{array}{l}1: 3136 \\
2316-4368\end{array}$ \\
\hline
\end{tabular}

*Both infants' initial blood spots were positive but had IRT values considered to be within the normal range on follow up. 
Table 2 Analysis of false negative specimens

\begin{tabular}{|c|c|c|}
\hline & $\begin{array}{l}\text { West } \\
\text { Midlands }\end{array}$ & Wales \\
\hline $\begin{array}{l}\text { Negative on frst screen } \\
\text { Positive on first screen, }\end{array}$ & 0 & 1 \\
\hline $\begin{array}{l}\text { negative on second screen } \\
\text { Negative on first screen }\end{array}$ & 2 & 0 \\
\hline but had meconium ileus & 0 & 1 \\
\hline
\end{tabular}

infants had positive first spot IRT results but on follow up the second spots were considered to be normal. These two infants were diagnosed within 12 months on the basis of clinical symptoms but in both cases the paediatrician was unaware of their IRT screening results. The second IRT value for the two infants was 625 and $500 \mathrm{ng} / \mathrm{ml}$ and these were done when the second spot IRT cut off point was $700 \mathrm{ng} / \mathrm{ml}$. In retrospect we found that lowering the cut off point to $600 \mathrm{ng} / \mathrm{ml}$ could not have increased the incidence of second spot false positive results. Further reduction of the cut off point to below $500 \mathrm{ng} / \mathrm{ml}$ would have more than doubled the incidence of false positive results. Thus the second spot positive IRT value was revised to $600 \mathrm{ng} / \mathrm{ml}$, and within three months after implementing this revision an infant with cystic fibrosis was diagnosed whose second spot IRT was $670 \mathrm{ng} / \mathrm{ml}$.

The incidence of cystic fibrosis based on specimens screened (positive and false negative) was similar in the West Midlands and in Wales $\left(\chi^{2}=0.07, \mathrm{df}=1 \mathrm{p}>0.1\right)$ but there was an underestimate for the West Midlands region due to the exclusion of most infants with meconium ileus. To date, five patients with meconium ileus have been excluded from the possibility of being screened.

There was also a pronounced regional difference in the incidence of first spot false positive results (table 1), being almost double in the West Midlands compared with Wales. This regional difference was not reflected in the false positive incidence after follow up. If 1000 $\mathrm{ng} / \mathrm{ml}$ was taken as the cut off point the first positive incidence fell to $0.31 \%$ and $0.17 \%$, respectively.

Fourteen infants in this study, both screened and unscreened, had meconium ileus. IRT was estimated on specimens taken at between 4 and 20 days of age from 11 of these children. Three of the specimens collected from infants of ages 7,12 , and 14 days were considered to be negative.

\section{COMPARISON OF THE INCIDENCE OF CYSTIC FIBROSIS DETECTED IN SCREENED AND UNSCREENED GROUPS}

There was more than a two-fold difference between fibrocystic infants not known to be at risk and detected by screening compared with those diagnosed on clinical grounds (table 3 ), and this was significant $\left(\chi^{2}\right.$ $=12.59, \mathrm{df}=1, \mathrm{p}<0.01)$. Analysis on the basis of
Table 3 Distribution of screened and unscreened fibrocystic patients

\begin{tabular}{lrr}
\hline & $\begin{array}{c}\text { West } \\
\text { Midlands }\end{array}$ & Wales \\
\hline $\begin{array}{lr}\text { Fibrocystic patients detected by screening: } \\
\text { Total No of screened } \\
\quad \text { specimens }\end{array}$ & 75817 & 52761 \\
$\begin{array}{l}\text { Infants not at risk } \\
\text { Infants with cystic fibrosis }\end{array}$ & 20 & 13 \\
$\quad$ sibling & 1 & 1 \\
$\begin{array}{l}\text { Infants with meconium ileus } \\
\text { Total }\end{array}$ & 2 & 0 \\
$\begin{array}{l}\text { Fibrocystic patients detected clinically: } \\
\text { Total No of unscreened }\end{array}$ & 23 & 14 \\
$\quad$ specimens & 89264 & 56125 \\
Detected on symptoms alone & 7 & 5 \\
Infants with cystic fibrosis & & \\
$\quad$ sibling & 2 & 3 \\
Infants with meconium ileus & 6 & 3 \\
Total & 15 & 11 \\
\hline
\end{tabular}

Five of the six patients with meconium ileus were admitted to Birmingham Children's Hospital and were consequently excluded from the West Midlands screening region.

*Excludes false negative results in screened infants initially detected clinically.

year of birth showed in all cases that there was a significant difference between screened and unscreened infants where no risk was suspected even back to 1985 ( 12 screened, four unscreened, $\chi^{2}=5 \cdot 85$, df $=$ $1, p<0.05)$. This difference just reached significance if infants known to be at risk because of meconium ileus or an affected sibling are included $\chi^{2}=3.98, \mathrm{df}=1, \mathrm{p}$ $<0.05)$.

\section{Discussion}

The specificity and reliability of the IRT screening test for cystic fibrosis obtained in this study were similar to those reported in earlier studies. ${ }^{1-38}$ The incidence of false positive results could be reduced by raising the cut off point of the assay to $1000 \mathrm{ng} / \mathrm{ml}$ on the first spot without loss of detection of any fibrocystic neonates. There does seem to be a regional difference for the incidence of false positive results, as consistently throughout this whole study, the percentage incidence of false positive spots screened has been almost twice as high with spots obtained from the West Midlands as those obtained from Wales. One possible reason for this difference might be due to differences in the nature of the Guthrie cards used to collect blood spots in the two regions. Preliminary studies done at the beginning of this investigation, however, were unable to show differences in the estimation of either standards or test specimens prepared on papers from the two regions. The age of the spots when analysed were similar ( 3 to 4 weeks old) as was the actual age at collection. We are thus unable to explain the reason for this difference.

The false negative incidence of four in $\mathbf{4 1}$ fibrocystic neonates does seem to be higher than has previously 
been reported. One of the four had meconium ileus which is not only virtually diagnostic for cystic fibrosis but has a known association with false negative IRT results.' For this reason spots from infants with meconium ileus have often been excluded from an assessment of the IRT test. We feel, however, that it is necessary to include such infants to give a true assessment of the test. The association between meconiun ileus and false negative IRT results may also be variable between populations. The false negative incidence obtained on all patients with meconium ileus (whether screened or unscreened) in this study was much lower than that reported by Duhamel et $a l^{9}$; three in 11 compared with six in seven. On the other hand, Wilcken $e t a \beta$ had no negative results on specimens from 13 infants with meconium ileus.

Two of the other four children missed on screening had positive IRT values on the first screen with both values over $1000 \mathrm{ng} / \mathrm{ml}$ but were negative on follow up and were therefore missed. Using the current cut off point of $600 \mathrm{ng} / \mathrm{ml}$ for the second specimen, one of the two would have been scored as positive. Ideally the specificity of the test could be improved if all infants with a positive first spot result could have a sweat test but this is not practical at present.

It is too early to report on the clinical value of the screening tests, which must await the detailed clinical follow up on the infants detected in this study. It is, however, clear that there has been a pronounced increase in the number of children who were not known to be at risk detected by screening compared with those detected on a clinical basis. Even comparing infants born in 1985 alone, there is a two-fold difference between the two groups, but mathematical distribution anomalies cannot be ruled out at present. Nevertheless, these findings do seem to confirm Warwick's suggestion that cystic fibrosis is underdiagnosed ${ }^{10}$ and that some affected infants may die without the diagnosis being made, even at necropsy.

We thank the consultant paediatricians in Wales and the West Midlands who have given care to all infants in the study and informed us of cases diagnosed clinically. We also thank the community midwives in both regions who collected the initial and repeat spots. We also thank Dr T Peters, department of medical statistics, University of Wales College of Medicine for his advice on the statistical analysis used in this paper.

This study was funded by a project grant from the Cystic Fibrosis Trust.

\section{References}

1 Crossley JR, Elliott RB, Smith PA. Dried blood spot screening for cystic fibrosis in the newborn. Lancet 1979;i:472-4.

2 Heeley AF, Heeley ME, King DN, Kuzemko JA, Walsh MP. Screening for cystic fibrosis by dried blood spot trypsin assay. Arch Dis Child 1982;57:18-21.

3 Wilcken B, Brown ARD, Urwin R, Brown DA. Cystic fibrosis screening by dried blood spot trypsin assay: results in 75000 newborn infants. J Pediatr 1983;102:383-7.

4 Wilson JMG, Jungner G. Principles and practice of screening for disease. Geneva: World Health Organisation, 1968.

5 Wilcken B, Chalmers G. Reduced morbidity in patients with cystic fibrosis detected by neonatal screening. Lancet 1985;ii:1319-21.

6 Dankert-Roelse JE, Te Meerman GJ, Martign A, Ten Kate LP, Knol K. Screening for cystic fibrosis: a comparative study. Acta Paediatr Scand 1987;76:206-14.

7 Bachmann C, Colombo J-P. Incidence of disorders tested by systematic screening: confidence limits and comparison of programmes. J Inher Metab Dis 1982;5:3-5.

8 Travert G, Duhamel JF. Neonatal screening for CF using IRT assay in dried blood spots: a four year experience in Basse-Normandie. In: Lawson D, ed. Cystic fibrosis horizons. Chichester: J. Wiley \& Sons, 1984:209.

9 Duhamel JF, Travert G, Delmas P, Brouard J, Venezia R. Special features of time related evolution in IRT blood levels in six of seven newborns with cystic fibrosis complicated by meconium ileus. In: Lawson D, ed. Cystic fibrosis Horizons. Chichester: J. Wiley \& Sons, 1984:208.

10 Warwick WJ. Prognosis for survival with cystic fibrosis. The effects of early diagnosis and cystic fibrosis centre care. Acta Paediatr Scand 1982;301:27-31.

Requests for reprints to: Dr H C Ryley, Department of Medical Microbiology, University of Wales College of Medicine, Heath Park, Cardiff CF4 4XN, Wales. 